\title{
From Queen Victoria to Sausage Pants: art in the superhospital
}

\author{
— Cite as: CMAJ 2018 January 8;190:E18-20. doi: 10.1503/cmaj.170721
}

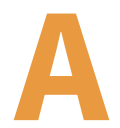

marble sculpture of Queen Victoria (1819-1901) held an important place at the original site of Montreal's Royal Victoria Hospital and in the public's heart. Patients, medical students, physicians, nurses and visitors caressed the figure while walking by, seeking luck from this royal cum patron saint. Made in 1895 by Countess Feodora Gleichen (1861-1922), the sculpture was exhibited at the hospital ${ }^{1}$ from 1897 until its transfer to "the Glen," the McGill University Health Centre superhospital that opened in 2015. Larger than lifesize, this monument was made to show the hospital founders' gratitude to the monarch and to map the Queen's symbolic values onto her namesake institution. Art, here in the form of the Queen, symbolized: the rising status of modern medicine in Quebec; conceptions of public health as stable and noble; and comfort, through the portrayal of a well-loved royal associated with motherhood, caregiving and endurance.

Today, the sculpture sits rather awkwardly in the main hallway of the Royal Victoria Hospital section of the Glen. The square plinth juts out into a busy walkway, tempting passersby to leave their paper cups on its edges. Despite its recent restoration, the marble monarch remains a relic of Canada's colonial past, historicizing the new building and acting as a foil against which the site-specific contemporary art can be understood.

Queen Victoria is dwarfed by 11 large public artworks scattered throughout the Glen. Paid for with 4.3 million dollars in public funds and chosen by government- and hospital-appointed committees, ${ }^{2,3}$ these new works reflect current trends in "hospital art" across the globe. As evinced by McGill University Health Centre press materials and art tours, these artworks "play an integral role in developing a truly healing

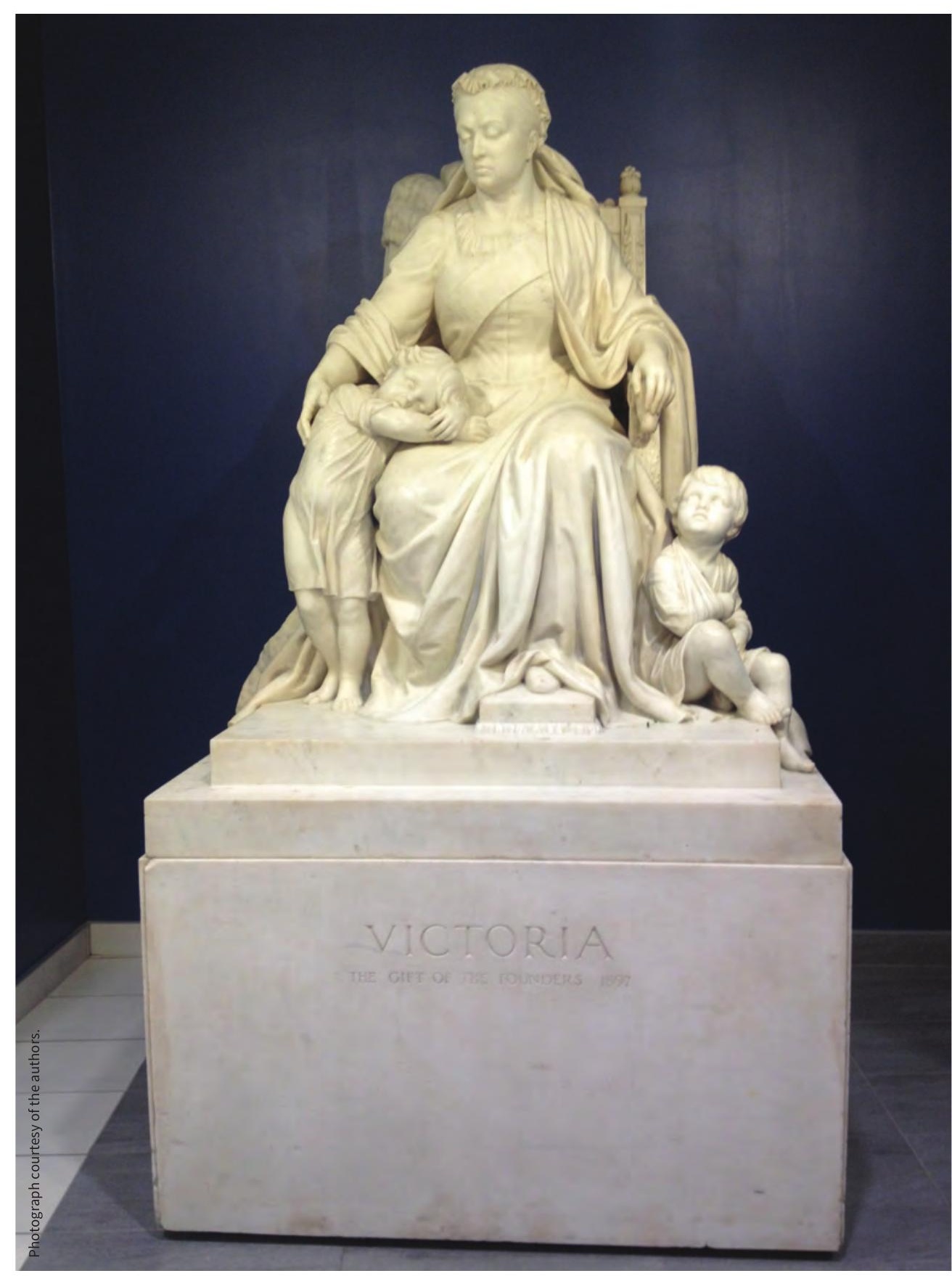

Photograph of the marble sculpture of Queen Victoria by Countess Feodora Gleichen (1895), Royal Victoria Hospital, Montréal, 2017. 
environment designed specifically for patients and their families" 3 and are intended to "comfort, encourage and inspire." ${ }^{4}$ In this article, we question whether such prescriptiveness is desirable. Is soothing and inspirational art the only appropriate choice for a hospital? Does it garner a sense of well-being that is not invoked by other works, like Queen Victoria?

The rhetoric framing public art at the McGill University Health Centre exemplifies how contemporary hospital art is often amalgamated into discourses of "healthy design." As a result, hospital art commissions tend toward a functionalist philosophy, ${ }^{5}$ ostensibly serving health recovery efforts by medical institutions. We submit that purpose-driven art is not the only nor necessarily the most effective - way to communicate a sense of well-being to the various populations that inhabit hospitals. ${ }^{6}$ Such prescriptive agendas can also disregard art's infinite possibilities, including its ability to make us think, laugh or be sad.

As health care architecture specialist Birgitte Louise Hansen noted, there is a "growing belief that patient-centred health care is about postponing the idea of illness, disease and death in the interests of the individual - the client."7 Recognizing that art and design can help construct a hospital's positive image, she contended that " $[\mathrm{h}]$ ospitals today are trying to look anything but 'scary'."' Although the desire for a healing environment is not new, ${ }^{8}$ the health care sector continues to explore the potential of "evidence-based design": scientifically based design practices that allegedly increase well-being, cost effectiveness and productivity in hospitals. ${ }^{9}$ Our preliminary research shows that the projected functions of hospital art are often subsumed within such "healthy design" philosophies.

Our investigation of contemporary art practices in European and North American hospitals evinces two trends that are also found in the McGill University Health Centre's commissions: medically themed art and art that corresponds to healthy design directives (with an emphasis on nature themes). The "medical art" at the McGill University Health Centre includes Josée Pedneault's Annedda, a series of murals displayed in the thoracic department depicting plants traditionally used for respiratory ailments; Cooke-Sasseville's Prendre le pouls,

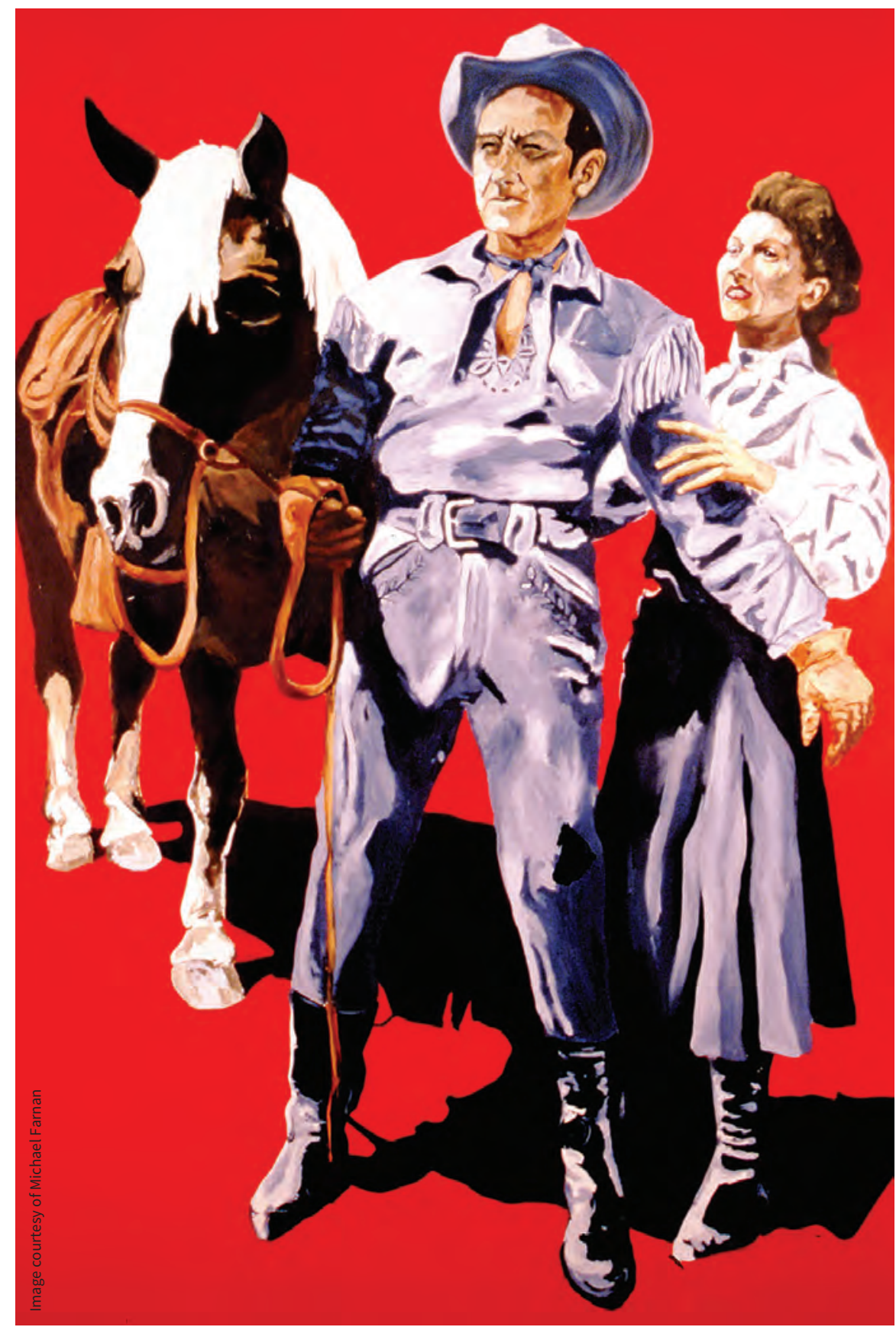

Michael Farnan, Sausage Pants, 2005. Oil on canvas. 54" $\times 80 "$.

an $8 \times 6 \mathrm{~m}^{2}$ stethoscope on an outdoor terrace; and Nicolas Baier's magnified 3D reproduction of human hemoglobin in stainless steel that hangs in the Research Institute. The website for the centre emphasizes the healing qualities of these artworks; for example, the stethoscope sculpture "represents the human dimension of medicine" and Baier's work "serv[es] the purpose of science which is to help, heal and save ...."10

The only new work indirectly tied to human suffering is Martha Townsend's Lux
Domum in the Cedars Cancer Centre, which was influenced by her sisters' experiences with cancer. However, the online description stresses the abstract mural's "comforting form" and that it is "designed to suggest associations between positive ideas."10 Importantly, there are no public artworks depicting human beings, although the imposing scale of the commissioned artworks affects the viewer's body. For instance, one may feel overwhelmed by standing within Linda Covit's $13 \times 16 \mathrm{~m}^{2}$ 
aluminum sculpture, Havre, at the front of the Glen - as one feels small beside Richard Serra's towering minimalist works yet the McGill University Health Centre proposes that it offers "a sense of support."10

Commissions of hospital art, like those at the Glen, differ from medically themed artworks that are admired in "elite" academic and art circles. Photographers Jo Spence, Annie Leibowitz and Matuschka are among many artists whose works invite viewers to contemplate human existence and question conventional illness metaphors. In general, the art shown in hospitals is less provocative - and that's fair enough because hospitals aren't art galleries after all.

In our opinion, what's distinct about art in hospitals is that one can opt in or out of the esthetic experience. Rather than being prescriptive, this opens up greater possibilities for experimentation, spontaneous interactions and multiple understandings of what art may offer. Although hospital art is increasingly oriented toward healthy design, medical themes and functionality, we shouldn't lose sight of the specificity of art as art. Art in hospitals maintains its raison d'être precisely when it does not follow treatment directives.

The sculpture of Queen Victoria is one such example, as is a well-loved painting from the Royal Victoria Hospital that has been in storage since the move to the Glen. Michael Farnan's Sausage Pants - displayed in the cardiology wing of the Royal Victoria Hospital from 2008 until 2015 was not intended for a hospital and does not have a medical theme. The work repre- sents a 1950s-era cowboy flanked by a horse and woman against a red background. Although responses to the painting varied in our informal polling of regulars at the Royal Victoria Hospital, most people smiled when it was mentioned and asked where it was now, as if inquiring after an old friend. Although many did not know the painting's title, most were aware of the artist's masterful shading of the cowboy's pants that marked him as well endowed. Is such an artwork appropriate for a hospital? Does its lack of ties to medicine or healing make it unacceptable? Is its vulgarity funny or offensive?

This beloved example shows that there is great power to the value of disruption, humour and chance in art that is not programmatic. Sausage Pants is engaging for hospital users despite not fitting into typical government or hospital board guidelines. Hospital art is too often burdened by the impossible demand to soothe a hospital's diverse population; hampered by its function as a landmark; and limited by its role in promoting a hospital as patient-centred. Sausage Pants, on the other hand, is free to be what it is. We hope to see it back on the walls soon.

\section{Tamar Tembeck PhD}

Media@McGill, Department of Art History and Communication Studies, McGill

University, Montréal, Que.

\section{Mary Hunter PhD}

Department of Art History and

Communication Studies, McGill

University, Montréal, Que.

\section{References}

1. Neville T. The Royal Vic: the story of Montreal's Royal Victoria Hospital, 1894-1994. Montréal: McGill-Queen's University Press; 1994:44-8.

2. Politique d'intégration des arts à l'architecture. Québec: Culture et Communications Québec. Available: www.mcc.gouv.qc.ca/index.php?id=6089 (accessed 2017 Aug. 1).

3. Public art at the Glen: a walking tour of art on display at the Glen Site. Montréal: McGill University Health Centre; 2015. Available: https://muhc.ca/ muhc-heritage/page/public-art-glen (accessed 2017 Aug. 1).

4. McGill University Health Centre unveils the two largest public art works commissioned for the Glen site. Montréal: McGill University Health Centre; 2013. Available: https://muhc.ca/newsroom/ news/muhc-unveils-two-largest-public-art-works -commissioned-glen-site (accessed 2017 Aug. 1).

5. MacNaughton J. Art in hospital spaces. Int J Cult Policy 2007;13:85-101.

6. Cork R. The healing presence of art. New Haven (CT): Yale University Press; 2012.

7. Hansen BL. A nice picture is not enough: research on the social and cultural context of health care. In: Brouwer M, Kempers B, Wagenaar C. The collection: 25 years of art projects in care institutions 1985-2009. Amsterdam: SKOR; 2009:93.

8. Theodore D. Better design, better hospitals. CMAJ 2016;8:902-3.

9. An introduction to evidence-based design: exploring healthcare and design. Concord (CA): Center for Health Design; 2015.

10. Public Art at the Glen. Montréal: McGill University Health Centre; 2015. Available: https://muhc.ca/ muhc-heritage/Glenpublicart (accessed 2017 Aug. 1).

This article has been peer reviewed.

Acknowledgement: The authors thank the Social Sciences and Humanities Research Council of Canada for supporting elements of this research through an Insight Development Grant for the Encountering Art in Hospitals project. 